\title{
A Dual Role of P53 in Regulating Colistin-Induced Autophagy in PC-12 Cells
}

\begin{abstract}
Ziyin Lu ${ }^{1,2}$, Chunli Chen ${ }^{1}$, Zhiyong $W^{1}{ }^{1}$, Yusong Miao ${ }^{1}$, Ishfaq Muhammad ${ }^{1}$, Liangjun Ding ${ }^{1}$, Erjie Tian ${ }^{1}$, Wanjun $\mathrm{Hu}^{1}$, Huilin $\mathrm{Ni}^{1}$, Rui $\mathrm{Li}^{1}$, Bo Wang ${ }^{1}$ and Jichang $\mathrm{Li}^{1}{ }^{13 *}$

${ }^{1}$ Department of Veterinary Pharmacology and Toxicology, College of Veterinary Medicine, Northeast Agricultural University, Harbin, China, ${ }^{2}$ Department of Animal Production, College of Life Engineering, Shenyang Institute of Technology, Fushun, China, ${ }^{3}$ Heilongjiang Key Laboratory for Animal Disease Control and Pharmaceutical Development, Harbin, China
\end{abstract}

This study aimed to investigate the mechanism of p53 in regulating colistin-induced autophagy in PC-12 cells. Importantly, cells were treated with $125 \mu \mathrm{g} / \mathrm{ml}$ colistin for 12 and $24 \mathrm{~h}$ after transfection with p53 siRNA or recombinant plasmid. The hallmarks of autophagy and apoptosis were examined by real-time PCR and western blot, fluorescence/immunofluorescence microscopy, and electron microscopy. The results showed that silencing of p53 leads to down-regulation of Atg5 and beclin1 for $12 \mathrm{~h}$ while

OPEN ACCESS

Edited by:

Shruti Shukla,

Dongguk University Seoul,

South Korea

Reviewed by:

Sapna Sedha,

National Institute of Occupational Health (ICMR), India

Laxmi Ahirwal,

Dr. Hari Singh Gour University, India

${ }^{*}$ Correspondence: Jichang $L$

lijichang@neau.edu.cn

Specialty section:

This article was submitted to Predictive Toxicology,

a section of the journal

Frontiers in Pharmacology

Received: 09 August 2017 Accepted: 11 October 2017 Published: 27 October 2017

Citation:

Lu Z, Chen C, Wu Z, Miao Y, Muhammad I, Ding L, Tian E, Hu W, Ni H, Li R, Wang B and Li J (2017) A Dual Role of P53 in Regulating Colistin-Induced Autophagy in PC-12 Cells. Front. Pharmacol. 8:768. doi: 10.3389/fphar.2017.00768 up-regulation at $24 \mathrm{~h}$ and up-regulation of p62 noted. The ratio of LC3-II/I and autophagic vacuoles were significantly increased at $24 \mathrm{~h}$, but autophagy flux was blocked. The cleavage of caspase3 and PARP (poly ADP-ribose polymerase) were enhanced, while PC-12-sip53 cells exposed to 3-MA showed down-regulation of apoptosis. By contrast, the expression of autophagy-related genes and protein reduced in p53 overexpressing cells following a time dependent manner. Meanwhile, there was an increase in the expression of activated caspase 3 and PARP, condensed and fragmented nuclei were evident. Conclusively, the data supported that silencing of p53 promotes impaired autophagy, which acts as a pro-apoptotic induction factor in PC-12 cells treated with colistin for $24 \mathrm{~h}$, and overexpression of p53 inhibits autophagy and accelerates apoptosis. Hence, it has been suggested that p53 could not act as a neuro-protective target in colistin-induced neurotoxicity.

Keywords: colistin, autophagy, p53, PC-12 cells, apoptosis

\section{INTRODUCTION}

Colistin (polymyxin E) is the first choice in respect to infections caused by multi-drug-resistant Gram-negative bacteria (MDR-GNB; Bialvaei and Samadi Kafil, 2015), including Pseudomonas aeruginosa, Acinetobacter baumannii, Klebsiella pneumoniae (Walkty et al., 2009). It has also been determined to be potentially active against several mycobacterial species, such as Mycobacterium tuberculosis (Falagas and Kasiakou, 2005). However, the toxicity (including neurotoxicity and nephrotoxicity) had a direct influence on the effectiveness of colistin in clinic. Its potential neurotoxicity can cause various complications such as perplexity, facial and peripheral paresthesia, muscles weakness, loss of balance, and dyssynergia after intravenous administration of colistin methanesulfonate (CMS, the inactive pro-drug of colistin; Falagas and Kasiakou, 2006; Weinstein et al., 2009; Wahby et al., 2010; Honore et al., 2013). Our colleagues studied that colistin-induced 
neurotoxicity triggered autophagy and apoptosis in PC-12 cells, and that apoptosis was affected by the control of autophagy (Jiang et al., 2014; Zhang et al., 2015). Importantly, our previous study showed that $\mathrm{p} 53$ participates in autophagy and apoptosis in colistin-treated PC-12 cells (Zhang et al., 2016). The PC-12 cell line is derived from pheochromocytoma of the rat adrenal medulla and it is commonly used as a neural differentiation and neurosecretion model (Sasaki et al., 2002; Chen et al., 2013).

Autophagy is a conserved process in which the cytoplasmic contents are first directed toward elimination or turnover in membrane-bound compartments (Pimkina et al., 2009), and then broken down by the lysosomal system. It serves as a protective mechanism against the cellular stress induced by chemotherapy (Ryan, 2011), and also a contributing factor in cell death due to lack of energy. The current evidence also suggested that autophagy indirectly facilitate cell death (Wang et al., 2011). Apoptosis is a morphological and biochemical description of the major mode of a physiological cell death (Kerr et al., 1972); it has been widely appreciated as a key mechanism of regulated death, involved in cell damage/stress and normal development and morphogenesis (Nikoletopoulou et al., 2013). Both apoptosis and autophagy are important in the normal development, physiology and pathology of the cells, and critical in deciding the fate of the cells (Thorburn, 2008). P53 is a tumor suppressor protein, it can trigger cell cycle arrest, allow DNA damage repair and can promote apoptosis when cells are challenged by severe irreparable insults (Maiuri et al., 2010). P53-induced autophagy may either contribute to cell death (Crighton et al., 2007) or constitute a physiological cellular defense response (Amaravadi et al., 2007).

\section{MATERIALS AND METHODS}

\section{Reagents and Antibodies}

Colistin sulfate $(20,195 \mathrm{U} / \mathrm{mg})$ was purchased from SigmaAldrich (lot number 095K1048; St. Louis, MO). Fetal bovine serum (FBS) was obtained from Gibco BRL (Gaithersburg, MD, USA) and Dulbecco's modified Eagle's medium (DMEM), Lipofectamine $2000^{\mathrm{TM}}$, and opti-MEM were obtained from Life Technologies Corporation (Grand Island, NY, USA). 4',6diamidino-2-phenylindole (DAPI), 3-MA (autophagy inhibitor) and bafilomycin A1 (BFA) were purchased from Sigma Chemical Co. (St. Louis, Missouri, USA). Primary monoclonal antibodies of anti-beclin1, anti-LC3-II/I (microtubule-associated protein1 light chain 3) and anti-caspase3 were purchased from Cell Signaling Technology (Beverly, MA). Anti- $\beta$-action rabbit monoclonal antibody and secondary antibodies (horseradish peroxidase [HRP]-labeled goat anti-rabbit IgG) were obtained from Beijing Zhongshan Golden Bridge Biotechnology Co. Ltd. (Beijing, China).

\section{Cell Lines and Culture}

Rat PC-12 cells were obtained from the Cell Bank of Type Culture Collection, Shanghai Institute of Cell Biology, Chinese Academy of Sciences. The cells were cultured at $37^{\circ} \mathrm{C} 10 \%$ FBS/DMEM in $5 \% \mathrm{CO}_{2}$ atmosphere in a $\mathrm{CO}_{2}$ incubator as described previously (Jiang et al., 2014).

\section{RNAi and Plasmids}

Small interfering RNAs targeting p53 were obtained from GenePharma Co. Ltd (Shanghai, China). The siRNA sequences used were as follows: p53 siRNA (sense: $5^{\prime}$-CCUGUGCAGUUGUGGGUCATT- $3^{\prime}$ and antisense: $5^{\prime}$ UGACCCACAACUGCACAGGTT-3' ${ }^{\prime}$ ). Negative control siRNA (sense: 5'-UUCUCCGAACGUGUCACGUTT-3' and antisense: $5^{\prime}$-ACGUGACACGUUCGGAGAATT- $\left.3^{\prime}\right)$. The pcDNA3.1(+)p53 plasmid was cloned via the insertion of the p53 gene sequence (GenBank Accession No: NM_030989.3) into pcDNA3.1(+). In addition, total mRNA from PC-12 cells was used as a template for cDNA and was used to amplify the p53-coding sequence. The p53 specific forward and reverse primers were forward 5'-CGCGGATCCACCATGGAGGATTCACAGTCGG-3' and reverse $5{ }^{\prime}$-CCGCTCGAGTCAGTCTGAGTCAGGCCCC-3', respectively. The amplified p53-coding sequence was digested with BamHI and XhoI, and then ligated into BamHI and XhoI digested pcDNA3.1(+). The sequence of pcDNA-p53 was confirmed by Comate BioTech.

\section{Transfection and Analysis}

PC-12 cells were seeded onto 6-well plates at a density of $5 \times 10^{5}$ cells per well for $24 \mathrm{~h}$ until the confluence reached $60-80 \%$. Lipofectamine $2000^{\mathrm{TM}}$ reagent was used for transfection according to the manufacturer's instructions. For each transfection, $75 \mathrm{pmoL}$ of $\mathrm{p} 53 /$ control siRNA or $2.5 \mu \mathrm{g}$ of pcDNA3.1(+)-p53/pcDNA3.1(+) was prepared and overlaid onto the cells separately in DMEM medium and incubated for $6 \mathrm{~h}$ at $37^{\circ} \mathrm{C}$ in a $\mathrm{CO}_{2}$ incubator. Then, the medium was removed and replaced with $10 \%$ FBS/DMEM and after $42 \mathrm{~h}$, the p53 silencing or overexpression efficiency was evaluated by western blot. The control siRNA and pcDNA3.1(+) were used as negative controls (Lu et al., 2017b).

\section{Immunofluorescence Microscopic Examination}

The PC-12 cells were pre-transfected with p53 siRNA or pcDNA3.1(+)-p53 for $24 \mathrm{~h}$ following the treatment with colistin $(125 \mu \mathrm{g} / \mathrm{mL})$ for 12 and $24 \mathrm{~h}$ for immunocytochemistry. Briefly, the cells were fixed in $4 \%$ paraformaldehyde for $20 \mathrm{~min}$ at $37^{\circ} \mathrm{C}$, washed with $0.2 \%$ TritonX-100 in PBS, and permeabilized with $1 \%$ TritonX-100 for $30 \mathrm{~min}$ at $37^{\circ} \mathrm{C}$. Then, the cells were washed in PBS and incubated in 5\% bovine serum albumin (BSA) for $2 \mathrm{~h}$ in blocking buffer. Cells were incubated with p53 or LC3 antibodies (1:150 dilution) overnight at $4^{\circ} \mathrm{C}$, washed twice with PBS, followed by incubation with FITC-conjugated goat antirabbit IgG (1:400 dilution) for $1 \mathrm{~h}$ and $2.5 \mu \mathrm{g} / \mathrm{mL}$ DAPI nuclear stain for $20 \mathrm{~min}$ at $37^{\circ} \mathrm{C}$. The expression of LC3 was examined under a fluorescence microscope (Nikon Eclipse TE 2000U). The percentage of cells positive for LC3 punctate staining was calculated from counting 100 cells for each experimental group $(n=3)$ as explained in our previous study (Lu et al., 2017c).

\section{Real-Time PCR}

Real-Time PCR (RT-PCR) was performed to analyze gene expression using a Biosystem 7500 Real-Time PCR System thermocycler and FastStart Universal SYBR Green Master (ROX) 
from Roche. Total RNA was extracted using TRI reagent, and $1 \mu \mathrm{g}$ of RNA was reverse transcribed with a Transcriptor First Strand cDNA Synthesis Kit. Oligo nucleotide primers (Table 1) for beclin1, Atg5 and p62 were designed by Sangon Biotech (Shanghai, China), based on the sequences available in NCBI database. Each sample was analyzed in triplicate. The fold change in gene expression was calculated using the $\Delta \Delta$ cycle time $(\mathrm{Ct})$ method (Livak and Schmittgen, 2001) after the expression level of $\beta$-actin was normalized.

\section{Western Blot}

Western blot procedure was carried out as mentioned in our earlier study (Lu et al., 2017a). PC-12 cells were pre-treated as above. To prepare the protein lysates, cells were washed twice with cold PBS, and the total protein extracts were prepared in radio-immunoprecipitation assay (RIPA) lysis buffer containing $0.1 \%$ Non-idet P-40 and $0.5 \mathrm{mM}$ PMSF, followed by highspeed centrifugation $(12,000 \times \mathrm{g}$ for $30 \mathrm{~min})$ at $4^{\circ} \mathrm{C}$. Then, the supernatant protein content was determined using BCA protein assay kit (Dai et al., 2013). Equivalent amounts of protein were separated in a $10-15 \%$ gel by SDS-polyacrylamide gel electrophoresis (SDS-PAGE) run on $120 \mathrm{v}$ for $1 \mathrm{~h}$, and then transferred onto nitrocellulose (NC) membranes run on $120 \mathrm{v}$ for $90 \mathrm{~min}$. After blocking in 5\% non-fat dried milk-TBST (25 mM Tris- $\mathrm{HCl}, 150 \mathrm{mM} \mathrm{NaCl}, 0.1 \%$ Tween-20; $\mathrm{pH}$ 7.4) at room temperature for $1 \mathrm{~h}$, the membranes were incubated overnight on a shaker at $4{ }^{\circ} \mathrm{C}$ with primary antibodies against: p53 (1:400 dilution), Atg5 (1:500 dilution), LC3-II/I (1:1,000 dilution) and $\beta$-actin (1:1,000 dilution) at $4^{\circ} \mathrm{C}$. The secondary anti-mouse or anti-rabbit IgG peroxidase antibody (1:5,000 dilution) was incubated at room temperature for $1 \mathrm{~h}$, and the blots were developed using enhanced chemiluminescence (ECL) detection (Amersham-Pharmacia Biotech). The level of immunoreactivity was assessed as a peak intensity using an image capture and analysis system (GeneGnome, Syngene, UK). The anti- $\beta$-actin antibody was used to control the protein quality and ensure equal loading.

\section{Electron Microscopy}

Cells were fixed overnight in $2.5 \%$ glutaraldehyde. They were washed with PBS twice and post-fixed in $1 \%$ osmium tetroxide at $4^{\circ} \mathrm{C}$ for $1 \mathrm{~h}$. Next, the cells were dehydrated by ethanol series and

TABLE 1 | Sequences of the oligo nucleotide primers for gene transcription analysis by real-time PCR.

\begin{tabular}{|c|c|c|}
\hline Gene & Primer sequence & Product length (bp) \\
\hline \multirow[t]{2}{*}{ Atg5 } & Forward 5' -CCCTGAAGACGGAGAGAAGA-3' & 152 \\
\hline & Reverse 5'-TGCTGATGTGAAGGAAGTTGTC-3' & \\
\hline \multirow[t]{2}{*}{ beclin1 } & Forward 5'-TGGAAATCACTCGTATCTGGAG-3' & 119 \\
\hline & Reverse 5'-CСАССТСТTCTाTGAАСТGСТ-3' & \\
\hline \multirow[t]{2}{*}{ p62 } & Forward 5'-CСTATTACCTGGCСTGTGGA-3’ & 102 \\
\hline & Reverse 5'-GTTCATCCGTTGTGCATGAG-3' & \\
\hline \multirow[t]{2}{*}{$\beta$-actin } & Forward 5' ACCGCAAATGCTTCTAAACC-3' & 192 \\
\hline & Reverse 5'-CCAATCTCGTCTTGTITATGC-3' & \\
\hline
\end{tabular}

$100 \%$ acetone, embedded in epoxy resins. The ultrathin sections were stained with uranyl acetate and lead citrate (Zhang et al., 2016), and then observed under a GEM-1200ES transmission electron microscope (JEOL Ltd., Tokyo, Japan).

\section{Hoechst 33258 Staining}

Hoechst 33258 staining was used to investigate the changes in nuclear morphology of apoptosis, observed by fluorescence microscopy. The cells were fixed with $4 \%$ paraformaldehyde for $10 \mathrm{~min}$ at $37^{\circ} \mathrm{C}$, washed with $\mathrm{PBS}$ and stained with $5 \mu \mathrm{g} / \mathrm{mL}$ Hoechst 33258 for $10 \mathrm{~min}$ in the dark. The production of blue fluorescence in condensed and fragmented nuclei was counted as apoptotic cells (Zhu et al., 2011).

\section{Statistical Analysis}

Data were obtained from three independent experiments and are presented as mean results \pm standard deviation $(S D)$. The significance was determined using one-way ANOVA followed by LSD and Dunnett's T3 test. The data were analyzed using the SPSS V17.0 statistical software (SPSS, Chicago, IL). Values $<0.05$ ( $p<$ $0.05)$ were considered statistically significant.

\section{RESULTS}

\section{Regulation of Colistin Induced Autophagy by Silencing of p53 in PC-12 Cells}

To elucidate the molecular mechanism of p53 in autophagy, PC12 cells were transfected with a p53-specific siRNA (sip53) or negative control siRNA (nc), and p53 was effectively silenced (Figure 1A). Figure 1B showed that p53 level in cytoplasm significantly decreased in PC- 12 cells after transfection with sip53 according to immunofluorescence staining.

We employed RT-PCR and western blot to determine autophagy-related genes and protein expression levels, respectively. Compared with colistin-treated group, the mRNA expression level of Atg 5 and beclin 1 were decreased at $12 \mathrm{~h}$ but significantly increased at $24 \mathrm{~h}$, whereas p62 mRNA levels were enhanced at 12 and $24 \mathrm{~h}$ (Figure 1C; all $p<0.01$ ). The western blot results showed that the ratio of LC3-II/I (a marker protein of autophagy) and other autophagy-related proteins significantly increased after colistin treatment for $24 \mathrm{~h}$ (Figure 1D), and these results were consistent with RT-PCR analysis.

LC3 antibody was used in immunofluorescence microscopy to detect changes of PC-12-sip53 cells. LC3-specific punctate staining (green dots) is indicative of autophagic vacuoles (AVs) formation. Figure 2A depicts immunofluorescence images that show absence of LC3 punctate in the control group. The number of LC3 punctate in PC-12-sip53 cells was less than the colistintreated PC-12-nc cells at $12 \mathrm{~h}$; whereas different sizes and stages of AVs were substantially increased in colistin-treated PC-12sip53 cells for $24 \mathrm{~h}$.

Moreover, we used transmission electron microscopy to observe the colistin-induced autophagy in PC-12-nc and PCsip53 cells. As illustrated in Figure 2B, colistin-untreated PC12 cells showed normal morphology, with intact nuclear and normal aggregation of organelles. After $12 \mathrm{~h}$ of treatment with colistin, there were a large number of autophagic vacuoles 


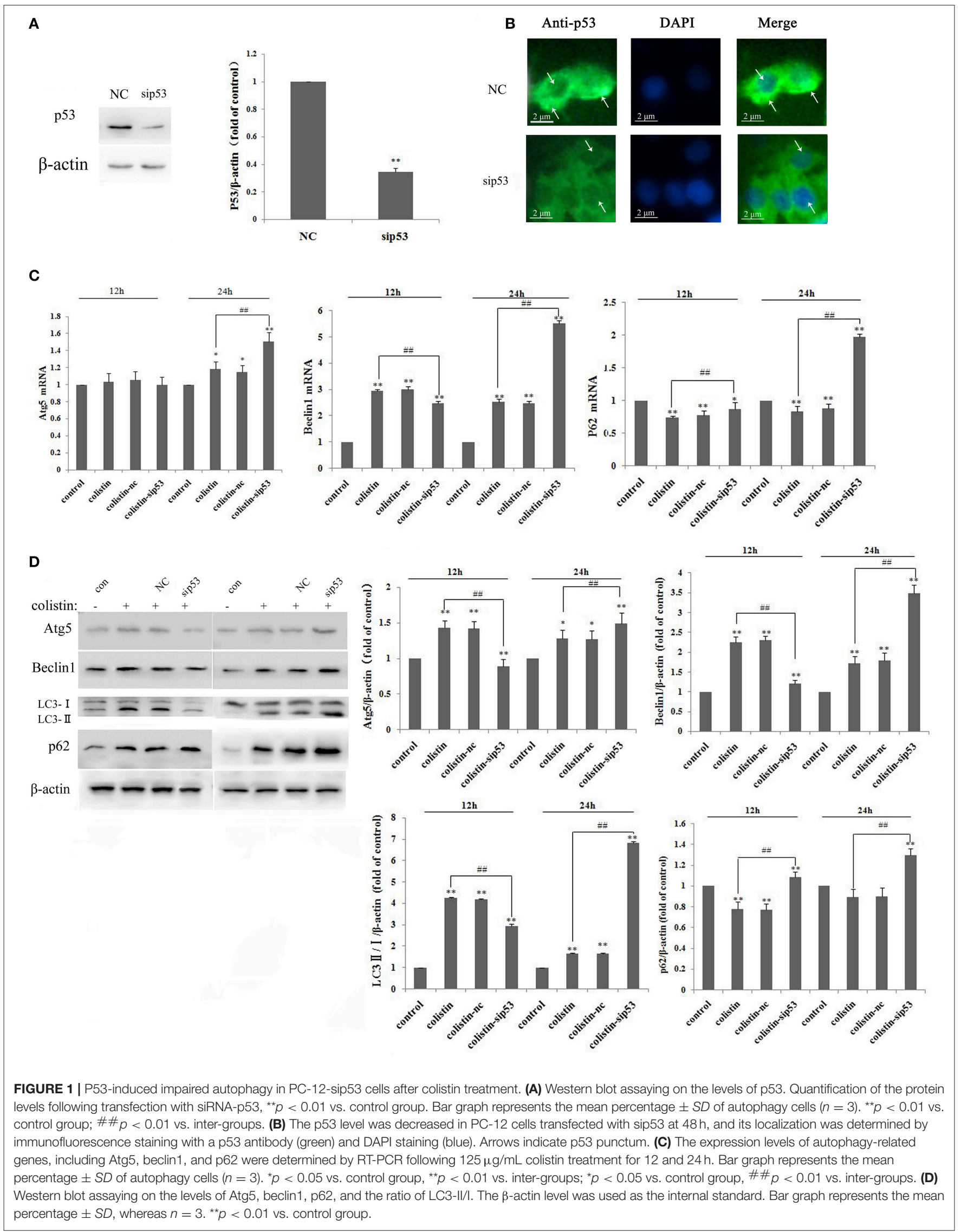




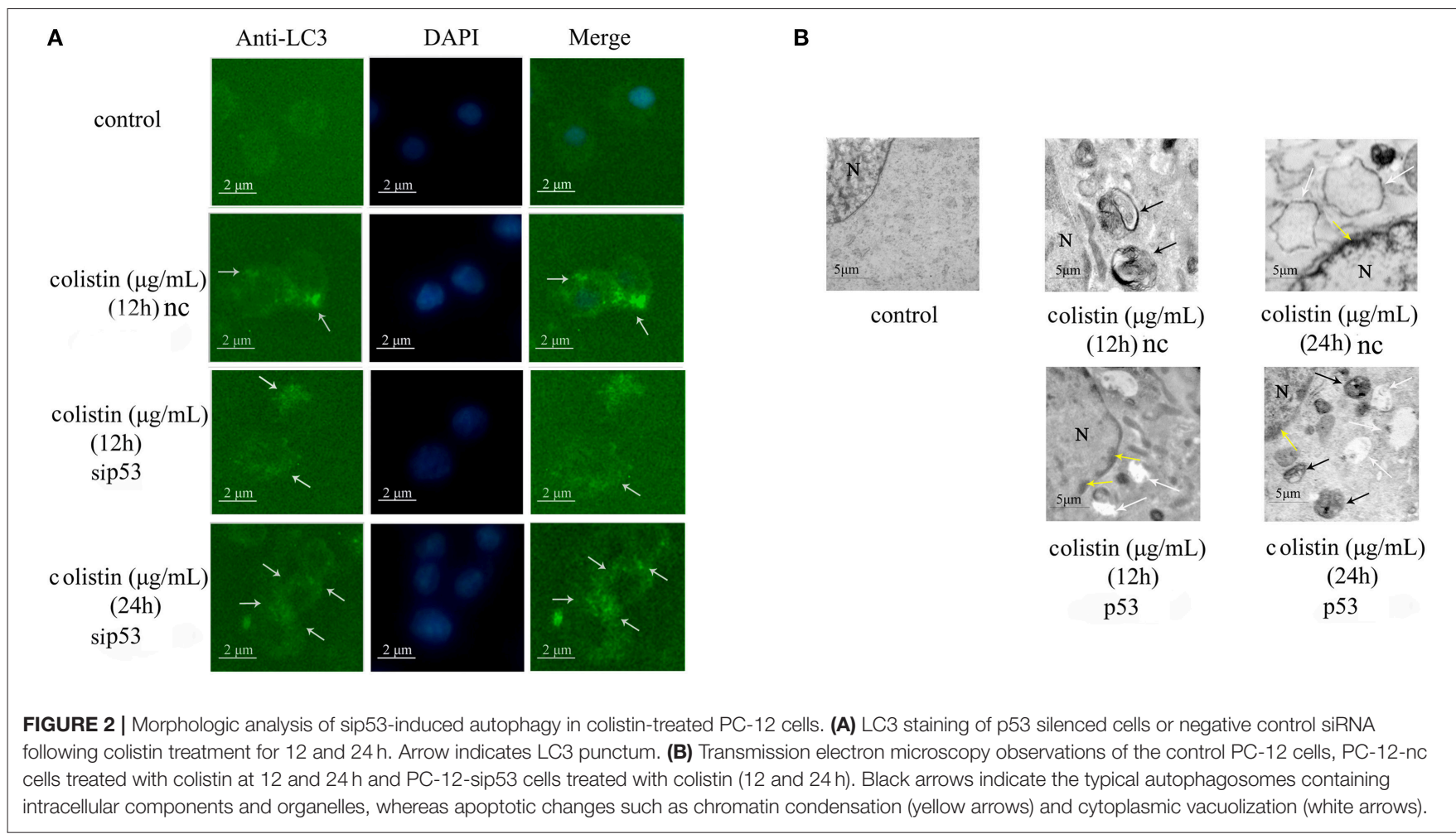

of characteristic double or multiple membranes intracellularly (containing cytoplasmic organelles and autophagosomes) in PC-12-nc cells, and nuclear chromatin concentration and cytoplasmic vacuolization were evident after $24 \mathrm{~h}$. Importantly, the number of AVs were diminished in colistin-treated PC12 -sip53 cells at $12 \mathrm{~h}$ as compared with colistin-treated PC12 -nc group, but at $24 \mathrm{~h}$ had an opposite phenomenon, formation of autophagic aggregates, and marginalization of chromatin has been increased. These data revealed that silencing of p53 cause down-regulation of autophagy in PC-12 cells following colistin treatment for $12 \mathrm{~h}$ and up-regulated autophagy for $24 \mathrm{~h}$.

To further elucidate the exact role of autophagy function after colistin treatment in PC-12-sip53 cells, we assessed autophagy flux. Its indexes were calculated as the difference in the amount of LC3-II with or without BFA (inhibitor of autophagosome and lysosomal fusion) intervention. As shown in Figures 3A,B, PC12 -nc cells treated with colistin after BFA ( $50 \mathrm{nM}$ in DMSO) had up-regulated the amount of LC3-II to about 1.5-fold as compared to without BFA. Whereas, inhibiting the fusion of lysosomes to autophagosomes in PC-12-sip53 cells exposed to colistin by BFA treatment did not increase the levels of LC3-II. These results suggested that silencing of $\mathrm{p} 53$ causes an impairment of autophagy flux in colistin-treated PC-12 cells, and it reduced the autophagic flux index of cells cultures from 1 to about 0.3 (Figure 3C).

To determine whether sip53-induced autophagy affect apoptosis in colistin-treated PC-12 cells, autophagy inhibitior 3-MA ( $5 \mathrm{mM})$ was used in PC-12-sip53 cells after colistin treatment for $24 \mathrm{~h}$. As shown in Figures $4 \mathrm{~A}-\mathrm{C}$ the silencing of p53 with colistin treatment for $24 \mathrm{~h}$ led to significantly decreased cleavage of caspase 3 and PARP in the presence of 3-MA. The data suggested that sip53-induced autophagy could activate apoptosis in PC-12 cells with colistin treatment.

The result of Hoechst 33258 staining shown in Figure 4D, colistin-treated PC-12-nc cells displayed indication of apoptosis; more nuclear fragmentation and chromatin condensation in colistin-treated PC-12-sip53 cells as compared to the control cells, in particular at both time points $(12 \mathrm{~h}$ and $24 \mathrm{~h})$, and showed peak results at $24 \mathrm{~h}$ (Figure 4D), but 3-MA pre-treatment exposure reduced chromatin condensation at $24 \mathrm{~h}$. As expected, sip53-induced autophagy was blocked by 3-MA results in downregulation of apoptosis in colistin-treated PC-12 cells.

\section{Regulation of Colistin-Induced Autophagy by Overexpression of p53 Protein in PC-12 Cells}

We used the manipulated genetic approach to gain further insight into the effect of p53 in colistin-induced neurotoxicity. As shown in Figure 5A, overexpression of p53 was mainly localized in the cytoplasm based on immunofluorescence staining. Quantitative densitometry of the western blot for p53 revealed that it was significantly up-regulated in the p53 overexpressing (PC-12-p53) group (Figure 5B, $p<0.01$ ). It is noted that expression levels of the positive regulators of autophagy (LC3-II/I and beclin1) were reduced after colistin treatment in PC-12-p53 cells in a timedependent manner, compared to the colistin-treated group; the p62 expression levels were significantly increased from 12 to $24 \mathrm{~h}$ 

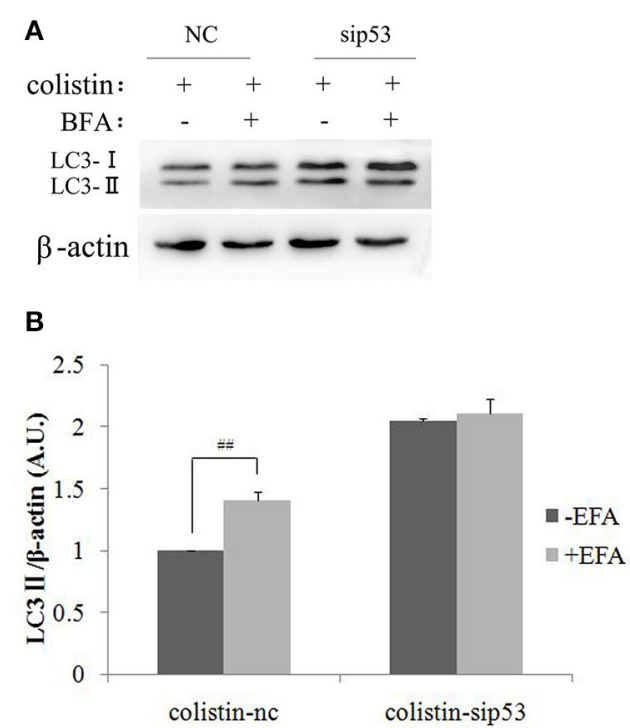

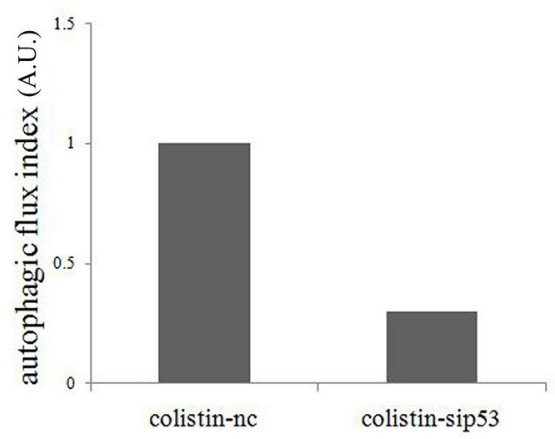

FIGURE 3 | Autophagic flux in PC-12-sip53 cells with colistin treatment. (A) PC-12 cells and PC-12-sip53 cells were treated with colistin (125 $\mu$ g/mL) for $24 \mathrm{~h}$, respectively after the absence and presence of BFA at $3 \mathrm{~h}$. (B) Western blot assaying on the levels of LC3-II/I. The $\beta$-actin level was used as the internal standard. Bar graph represents the mean percentage $\pm S D$, whereas $n=3$. $\# \# p<0.01$ vs. control group. (C) Autophagic flux indexes were calculated from the data illustrated in (B) as the difference in LC3-II/ $\beta$-actin ratios with or without BFA, expressed in arbitrary units (a.u.).
(Figures 5C,D all $p<0.01$ ). As shown in Figure 5D, cleavage of the pro-apoptotic proteins caspase 3 and PARP was pronounced after colistin treatment for 12 and $24 \mathrm{~h}$ in PC-12-p53 cells, and showed the highest level at $24 \mathrm{~h}$ as compared to the colistintreated group $(p<0.01)$. These data indicate that overexpression of p53 inhibits colistin-induced autophagy and has a promoting apoptotic effect on colistin-treated cells.

In addition to fluorescence microscopy, electron microscopy was employed to further observe colistin-induced autophagy in PC-12-pcDNA and PC-12-p53 cells. LC3 dots displayed as shown in Figure 6A, the autophagy biomarker LC3-II was reduced significantly by overexpression of p53 in colistintreated cells as compared to colistin-treated PC-12-pcDNA cells. Similarly, the images of electron microscopy shown in Figure 6B, overexpression of p53 in colistin treatment at $12 \mathrm{~h}$ led to few autophagic vacuoles, the further $12 \mathrm{~h}$ overexpression of $\mathrm{p} 53$ resulted in autophagosomes not obvious, and nuclear chromatin condensation and cytoplasmic vacuolization evident in colistintreated PC-12-p53 cells.

Furthermore, the Hoechst 33258 staining results showed that apoptosis gradually appeared and highly enhanced at $24 \mathrm{~h}$ as compared to the colistin-treated group (Figure 6C). These results lend further support to the verdict that overexpression of p53 inhibits colistin-induced autophagy and that it could accelerate apoptosis in PC-12 cells.

\section{DISCUSSION}

The ability of autophagic system to recycle nutrients, maintain cellular energy homeostasis, and degrade toxic cytoplasmic constituents (and bacterial infection) helps to keep cells alive during nutrient and growth factor deprivation and other stressful conditions (Levine and Klionsky, 2004). Therefore, understanding the complex functionality of autophagy induction is highly important. In our previous study, we proved that colistin $(125 \mu \mathrm{g} / \mathrm{mL})$ induces a high level of autophagy at $12 \mathrm{~h}$ and that autophagy can protect against the colistin-induced apoptosis (Jiang et al., 2014), and Zhang et al. reported that colistin increased the expression level of p53, and p53 involved in colistin-induced autophagy and apoptosis (Zhang et al., 2016). In this follow-up mechanistic study, we are interested in exploring whether p53-mediated autophagy plays a cell survival role in colistin-treated PC-12 cells and p53 could act as a target gene to protect against colistin-induced neurotoxicity.

p53, a tumor suppressor protein, plays a critical role in cellular response to acute stress. In the physiological condition, Mdm2-mediated ubiquitination and proteasomal degradation control p53 levels (Ryan, 2011). It rapidly undergoes reversible post-translational modifications for its stabilization in response to hypoxic, genotoxic, and oncogenic stress (Kruse and $\mathrm{Gu}$, 2009). Active p53 in the nucleus binds to the activator region of (and hence transactivate) plethora target genes involved in progression of cell cycle, apoptosis, and metabolism (Vousden, 2007). Additionally, p53 mediates transcription-independent extra nuclear onco suppressing functions (Green and Kroemer, 2009). In addition, p53 has a bidirectional modulatory action on autophagy, it has been demonstrated that p53-induced autophagy may lead to diametrically opposite results, such as physiological cellular defense response (Kerr et al., 1972) or causing cell death (Wang et al., 2011), depending on the p53 subcellular localization (Tang et al., 2015). In the present study, we used siRNA against p53 mRNA sequence to silence p53 in PC-12 
A

\begin{tabular}{|c|c|c|c|c|}
\hline \multirow[b]{2}{*}{ colistin: } & \multicolumn{2}{|c|}{ nc } & \multicolumn{2}{|c|}{ sip53 } \\
\hline & + & + & + & + \\
\hline 3-MA: & - & + & - & + \\
\hline
\end{tabular}

cPARP

$\beta$-actin

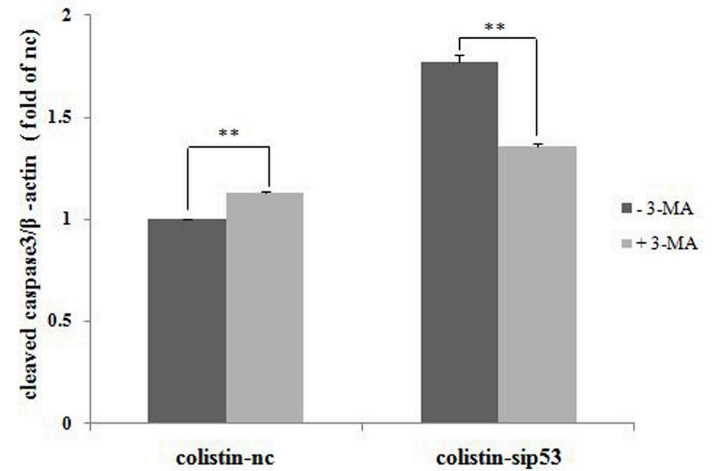

D

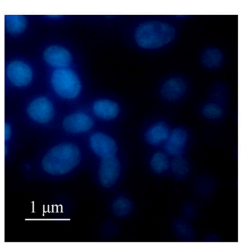

control

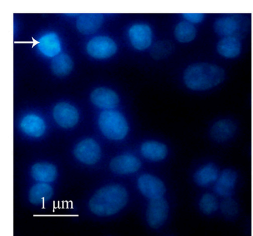

colistin $(\mu \mathrm{g} / \mathrm{mL})$

(12h)

nc

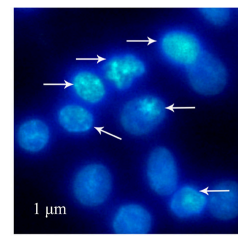

colistin $(\mu \mathrm{g} / \mathrm{mL})$

(24h)
C
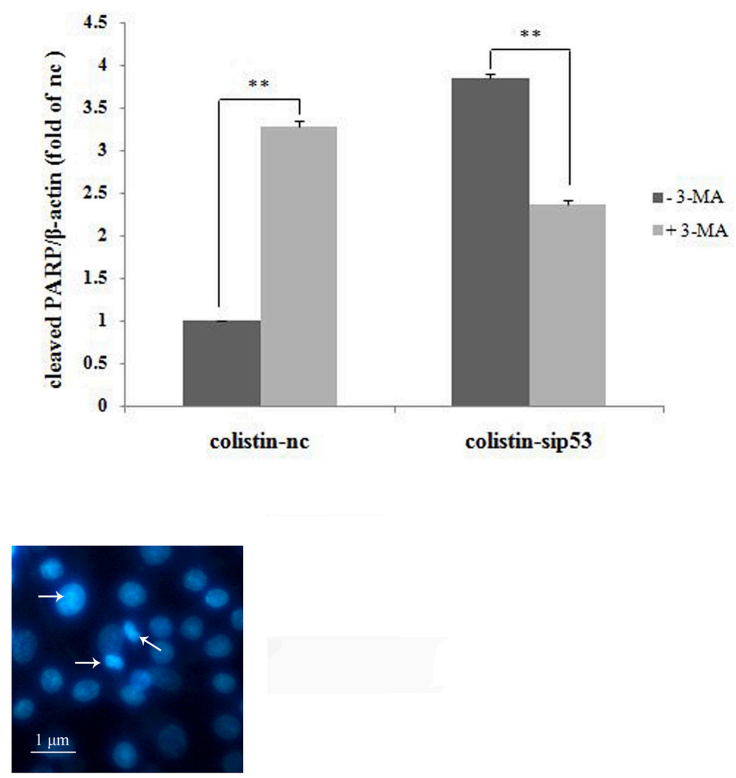

colistin $(\mu \mathrm{g} / \mathrm{mL})$

(12h)

$\operatorname{sip} 53$

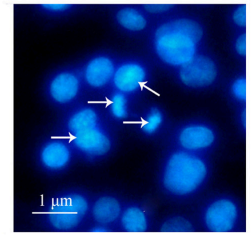

colistin $(\mu \mathrm{g} / \mathrm{mL})$

$(24 \mathrm{~h})+3-\mathrm{MA}$

FIGURE 4 | Apoptosis induced by the impaired autophagy in PC-12-sip53 cells treated with colistin. (A-C) Lysates of PC-12 cells and PC-12-sip53 cells, untreated or treated 3-MA for $1 \mathrm{~h}$ and further treated with colistin $(125 \mu \mathrm{g} / \mathrm{mL})$ at $12 \mathrm{~h}$, and then western blot assaying on the levels of cleaved caspase 3 and PARP. The $\beta$-actin level was used as the internal standard. Bar graph represents the mean percentage $\pm S D$, whereas $n=3$. ${ }^{* *} p<0.01$ vs. control group. (D) Changes of nuclear morphology in PC-12-sip53 cells with colistin treatment for 12 and $24 \mathrm{~h}$, incubated with or without 3 -MA by Hoechst 33258 staining. Arrows indicate fragmentation of the nuclear or karyopyknosis.

cells, and overexpressed p53 through a recombinant plasmid. Immunofluorescence staining was employed to observe the localization of p53, owing to the localization of p53 in cells directly related with its role in the regulation of autophagy or apoptosis. Especially, we found that siRNA/recombinantplasmid transfected into PC-12 cells was localized in the 
A

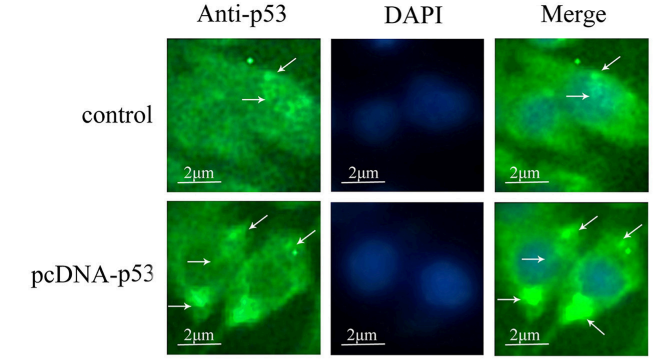

C

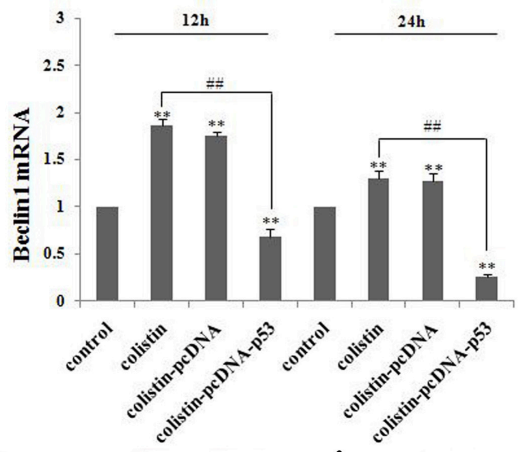

B
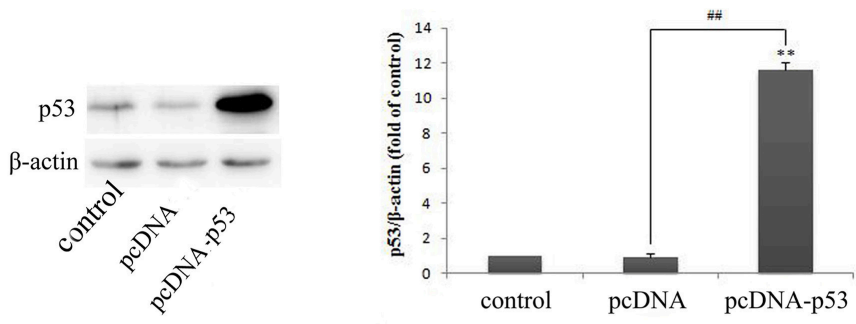

D

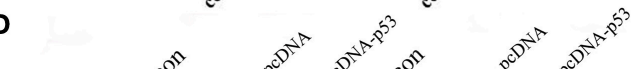
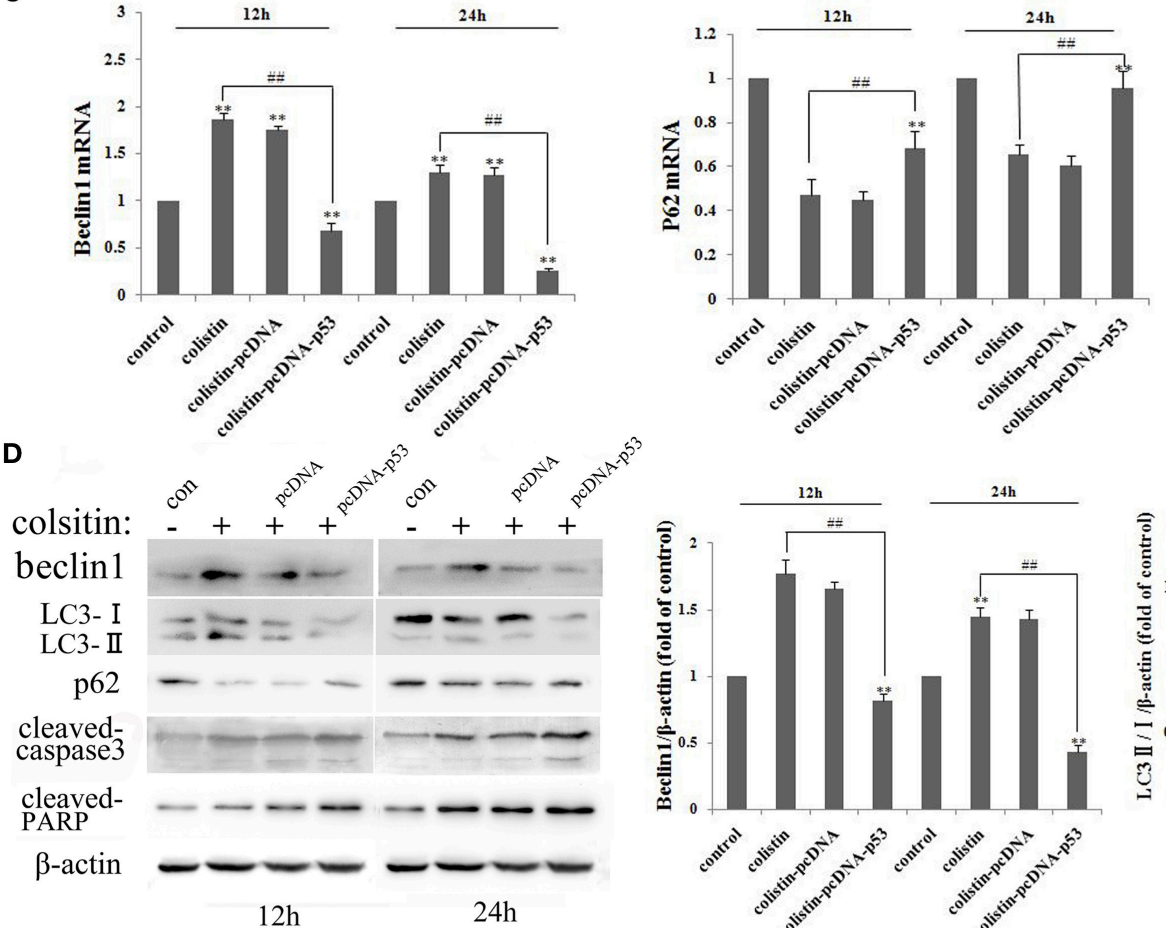

$12 \mathrm{~h}$

$24 \mathrm{~h}$
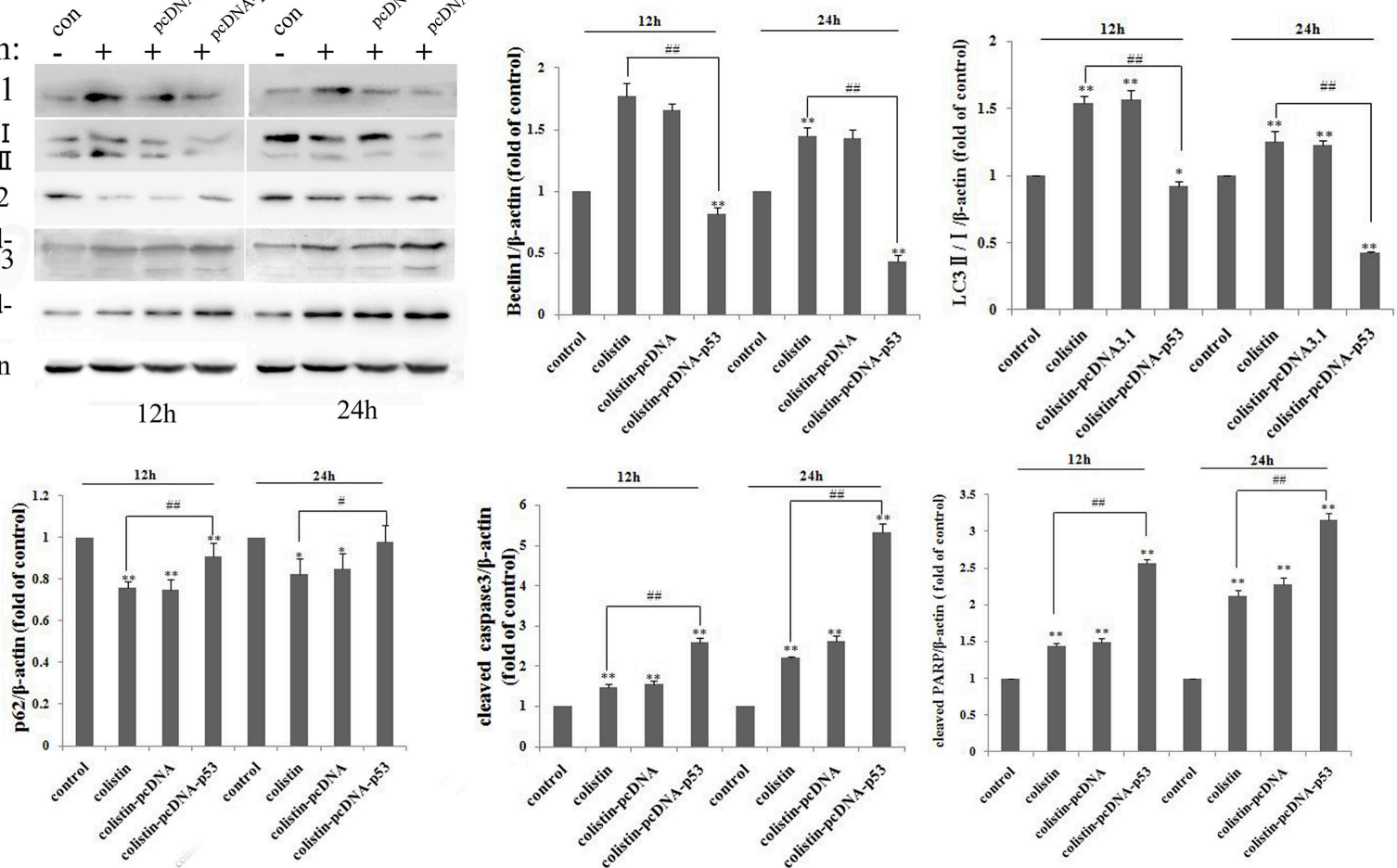

FIGURE 5 | Autophagy and apoptosis in PC-12-p53 cells after colistin treatment. (A) The expression levels of p53 were increased after transfection with a p53 recombinant plasmid, and p53 was localized by immunofluorescence staining with a p53 antibody (green) and nuclear staining with DAPI (blue). Arrows indicate p53 punctum. (B) The expression levels of p53 were assayed by western blot and quantification of the p53 protein levels. ${ }^{* *} p<0.01$ vs. control group; $\# \# p<0.01$ vs. inter-groups. (C) The expression levels of autophagy-related genes, including beclin1 and p62, were determined by RT-PCR following colistin treatment for 12 and $24 \mathrm{~h}$. Bar graph represents the mean percentage $\pm S D$ of autophagy cells $(n=3)$. ${ }^{\star *} p<0.01$ vs. control group; \#\# $p<0.01$ vs. inter-groups. (D) The expression levels of beclin1, p62, the ratio of LC3-II/I and cleaved caspase3 and PARP by western blot. The $\beta$-actin level was used as the internal standard, and shows the quantitative results of the expression levels, respectively. ${ }^{*} p<0.05 ;{ }^{* *} p<0.01$ vs. control group; $\# p<0.05$; $\# \# p<0.01$ vs. colistin alone group. 


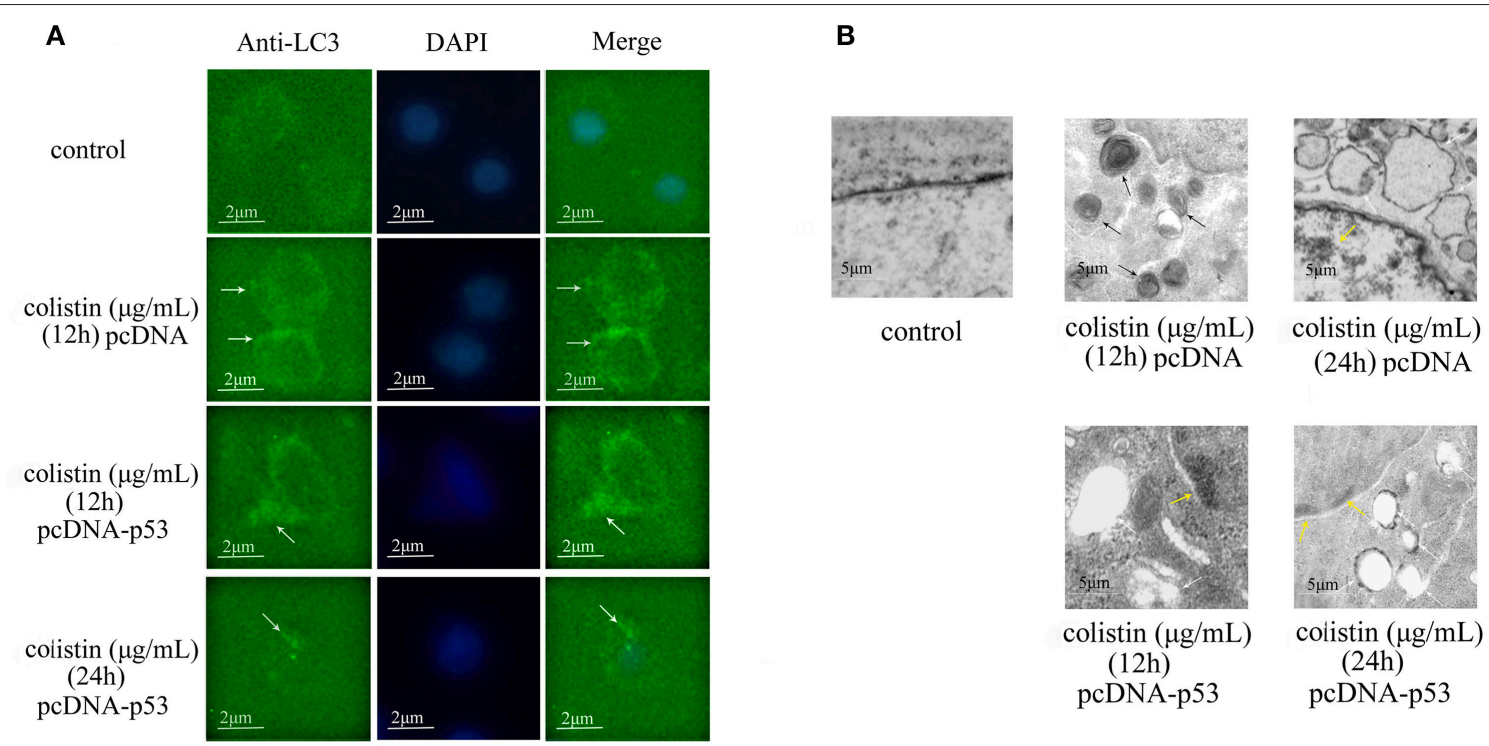

C

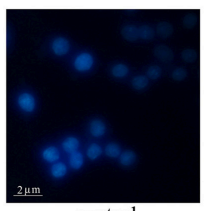

control

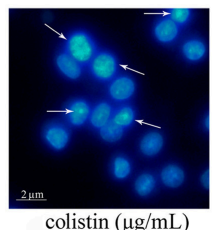

colistin $(\mu \mathrm{g} / \mathrm{mL})$

(12h)

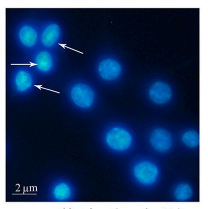

colistin $(\mu \mathrm{g} / \mathrm{mL})$ (12h) pcDNA

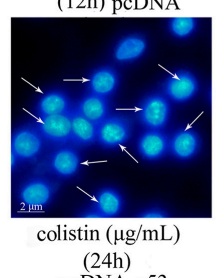

pcDNA-p53

FIGURE 6 | Morphologic analysis of p53-induced autophagy in colistin-treated PC-12-p53 cells. (A) LC3 staining of p53 overexpressing cells following $125 \mu$ g/mL colistin treatment for 12 and $24 \mathrm{~h}$. The control group was transfected with null vector. Arrow indicates LC3 punctum. (B) Transmission electron microscopy observations of the control PC-12 cells, PC-12-pcDNA cells treated with colistin at 12 and $24 \mathrm{~h}$ and PC-12-p53 cells treated with colistion (12 and $24 \mathrm{~h}$ ).

Autophagosomes, cytoplasmic vacuolization, and chromatin condensation in the treated groups are marked with black, white, and yellow arrows respectively.

(C) Hoechst 33258 staining showed changes in the nuclear morphology of cells treated with colistin for 12 and $24 \mathrm{~h}$. Arrows indicate fragmentation of the nuclear or karyopyknosis.

cytoplasm rather than in the nucleus. These results provide basis for future research to study the role of p53 in colistin-induced autophagy in PC12 cells.

It has been stated that cytoplasmic p53 acts as an inhibitor of autophagy via protein-protein interactions in mitochondria (Green and Kroemer, 2009), but acts as an activator of autophagy by transactivating its target genes after majority of p53 translocates to the nucleus in response to various forms of cellular stresses (Crighton and Ryan, 2004; Sui et al., 2011). P53 inhibits the negative regulator of autophagy mTOR (mammalian target of rapamycin) via AMP-activated protein kinase (AMPK) pathway activation, which in turn induces autophagy. Damageregulated autophagy modulator (DRAM) acts as a downstream gene of p53 in the control of autophagy and cell death. Besides the discovery of death-associated protein kinase 1 (DAPK-1) can favor autophagy induction by binding to LC3 (Harrison et al., 2008), the BH3 domain of beclin1 is phosphorylated by DAPK1 in the release of beclin 1 from $\mathrm{Bcl} 2 / \mathrm{Bcl}-\mathrm{xl}$, thereby stimulating autophagy (Zalckvar et al., 2009a,b). Notably, it is determined that p53 is a pro-autophagic factor that promotes autophagy via transactivating its target genes, but the pre-conditions are various cellular stresses to activate p53 and translocate it from cytoplasm into the nucleus (Green and Kroemer, 2009). However, autophagy inhibition by p53 is more obvious when the nuclear localization sequence of p53 is deleted, leading to a merely cytoplasmic p53 localization (Ryan, 2011). In our present 
study, it is clear from the results that autophagy-related genes and protein were inhibited in colistin-treated PC-12-sip53 cells at $12 \mathrm{~h}$, but opposite results occurred at $24 \mathrm{~h}$, indicating that p53 down-regulated autophagy in PC-12-sip53 cells at $12 \mathrm{~h}$ and upregulated autophagy at $24 \mathrm{~h}$. Our previous study showed that colistin induced the highest expression levels of nuclear p53 after $12 \mathrm{~h}$, but it induced the highest expression of cytoplasmic p53 at $24 \mathrm{~h}$ (Zhang et al., 2016). Thus, we inferred that the neurotoxicity of colistin acted as a stress/stimulation in PC12 cells to be a signal of p53 translocation into the nucleus, as p53 expression levels was reduced by siRNA, leading to the lower levels of p53-translocated into nucleus, thereby silencing of $\mathrm{p} 53$ down-regulated colistin-induced autophagy in PC-12 cells for $12 \mathrm{~h}$. Thereafter, cytoplasmic p53 plays a leading role in down-regulation of autophagy, while the relatively decreased cytoplasmic p53 level resulted in activation of autophagy in PC-12-sip53 cells at $24 \mathrm{~h}$.

The term "autophagic flux" describe that autophagy is a dynamic process (Zhou et al., 2017), and there is a dynamic equilibrium between autophagosome formation and clearance by lysosome. Actually, the rate at which material is cleared from the cell by autophagy is known as autophagy flux (Palumbo et al., 2016). The stability of LC3-II levels or amount of $\mathrm{AVs}$ is the net effect of both $\mathrm{AV}$ maturation and degradation (Komatsu et al., 2007). Therefore, the turnover of LC3 in autophagy has been widely used to monitor autophagic flux. In addition, there is an inverse relationship between p62/SQSTM1 levels and autophagy, because it is localized at the autophagic compartments and is degraded by autophagy-lysosomal pathway, and the accumulation of p62 accompanies the impairment of autophagy in cells (Komatsu et al., 2007; Mizushima and Yoshimori, 2007; Nakai et al., 2007; Mizushima et al., 2010). In current study, silencing of p53 up-regulated colistin-induced autophagy at $24 \mathrm{~h}$ (including the accumulation of AVs and significantly increased autophagy related genes), but the p62 level was dramatically increased, suggesting the blockage of lysosomal degradation. Therefore, we inferred that autophagy may be impaired. Indeed, our result showed an increase of colistin-induced LC3-II accumulation in PC-12 cells following the addition of the late-stage autophagy inhibitor (BFA). In contrast, the index of autophagic flux (be quantified by measuring LC3 turnover) is barely increased (Figure 3C), which indicated the impairment of sip53-induced autophagy in colistin-treated PC-12 cells. Our results are in line with the study conducted by Mizushima et al. that a concurrent increase has been noted in these markers, and being consistent with an impairment of autophagosome clearance (Mizushima et al., 2010), which is blocked in the last stage of autophagy. Furthermore, we found that colistin alone group had a significant elevating effect on autophagy that caused cell death in PC-12-sip53 cells, but pretreatment of the cells with 3-MA decreased apoptosis, suggesting a pro-apoptotic role of autophagy, as measured by cleavage of caspase 3 and PARP, 33258 staining (Figures 4A-D). These results suggested that apoptosis is able to be activated by silencing of p53 up-regulation autophagy, ultimately, leading to cell death rather than PC-12 cells survival. Furthermore, beclin1 is autophagy-related protein 6 and is a key factor in the initial formation of autophagosomes (Huang et al., 2016). However, another study demonstrated that beclin 1 is a substrate of caspase 3 and cleaved beclin 1 begins to promote apoptosis (Li et al., 2016), which may be also a cause of autophagic cell death in colistintreated PC-12-sip53 cells.

In the same manner, immunocytochemistry analysis showed that overexpression of p53 is only localized to the cytoplasm because the recombinant plasmid may be not integrated into the genome of PC-12 cells (Figure 5A). In a recent study, it has been reported that cytoplasmic p53 is an inhibitor of autophagy in cells, and it inhibits basal autophagy dependent protein-protein interactions in the mitochondria rather than transactivate its target genes (Tasdemir et al., 2008a,b). Indeed, in our study, down-regulation of the autophagy markers (including LC3 and beclin1) and up-regulating the cleavage of caspase 3 and PARP, and 33258 staining revealed that the increased expression levels of cytoplasmic p53 inhibited colistin-induced autophagy in PC12 cells and induced apoptosis (Figures 5C, D, 6A-C). A number of studies had confirmed that ROS generation, mitochondrial dysfunction and release of cytochrome $c$ were triggered by the neurotoxicity of colistin, which was the cause of apoptosis (Livak and Schmittgen, 2001; Jiang et al., 2014). The most cytoplasmic p53 translocate to mitochondria leading to the up-regulated expression of caspase 3 and ratio of $\mathrm{Bax} / \mathrm{Bcl} 2$ following colistin treatment, and thus accelerates apoptosis (Jiang et al., 2014). Meanwhile, colistin-induced neurotoxicity has a positive role in up-regulating the expression of p53, which eventually further speed up apoptosis. Thus, overexpression of cytoplasmic p53 up-regulation colistin-induced apoptosis maybe associated with p53-dependent mitochondrial apoptotic pathway in PC-12 cells.

\section{CONCLUSION}

This is the first study which demonstrated the silencing of p53 inhibits autophagy in PC-12 cells at $12 \mathrm{~h}$ and then upregulates defective autophagy from 12 to $24 \mathrm{~h}$, and eventually promotes apoptosis. Overexpression of p53 inhibits colistininduced autophagy, and accelerates apoptosis in a timedependent manner in PC-12 cells. Hence, we suggest that p53 plays a negative role in regulating colistin-induced autophagy in PC-12 cells and it could not act as a neuro-protective target in colistin-induced neurotoxicity.

\section{AUTHOR CONTRIBUTIONS}

JL supervised the whole experiments. ZL, CC, and ZW designed this study and contributed to the paper writing. YM, LD, ET, WH, $\mathrm{HN}, \mathrm{RL}$, and BW performed the practical work and completed the experiments. IM helped in revising and improving the language expression.

\section{ACKNOWLEDGMENTS}

This study was supported by the National Natural Science Foundation of China (31472240) and the Natural Science Fund of Heilongjiang Province (C201424). 


\section{REFERENCES}

Amaravadi, R. K., Yu, D., Lum, J. J., Bui, T., Christophorou, M. A., Evan, G. I., et al. (2007). Autophagy inhibition enhances therapy-induced apoptosis in a Myc-induced model of lymphoma. J. Clin. Invest. 117, 326-336. doi: 10.1172/JCI28833

Bialvaei, A. Z., and Samadi Kafil, H. (2015). Colistin mechanisms and prevalence of resistance. Curr. Med. Res. 31, 707-721. doi: 10.1185/03007995.2015.10 18989

Chen, W., Li, X., Jia, L., Wang, J., Zhang, L., Hou, D., et al. (2013). Neuroprotective activities of catalpol against CaMKII-dependent apoptosis induced by LPS in PC-12 cells. Br. J. Pharmacol. 169, 1140-1152. doi: 10.1111/bph.12200

Crighton, D., and Ryan, K. M. (2004). Splicing DNA-damage responses to tumour cell death. Biochim. Biophys. Acta 1705, 3-15. doi: 10.1016/j.bbcan.2004.09.001

Crighton, D., Wilkinson, S., and Ryan, K. M. (2007). DRAM links autophagy to p53 and programmed cell death. Autophagy 3, 72-74. doi: 10.4161/auto.3438

Dai, C., Li, J., and Li, J. (2013). New insight in colistin induced neurotoxicity with the mitochondrial dysfunction in mice central nervous tissues. Exp. Toxicol. Pathol. 65, 941-948. doi: 10.1016/j.etp.2013.01.008

Falagas, M. E., and Kasiakou, S. K. (2005). Colistin: the revival of polymyxins for the management of multidrug-resistant gram-negative bacterial infections. Clin. Infect. Dis. 40, 1333-1341. doi: 10.1086/429323

Falagas, M. E., and Kasiakou, S. K. (2006). Toxicity of polymyxins: a systematic review of the evidence from old and recent studies. Crit. Care 10:27. doi: $10.1186 /$ cc3995

Green, D. R., and Kroemer, G. (2009). Cytoplasmic functions of the tumour suppressor p53. Nature 458, 1127-1130. doi: 10.1038/nature07986

Harrison, B., Kraus, M., Burch, L., Stevens, C., Craig, A., Gordon-Weeks, P., et al. (2008). DAPK-1 binding to a linear peptide motif in MAP1B stimulates autophagy and membrane blebbing. J. Biol. Chem. 283, 9999-10014. doi: 10.1074/jbc.M706040200

Honore, P. M., Jacobs, R., Lochy, S., De, W. E., Van, G. V., Van, G. V., et al. (2013). Acute respiratory muscle weakness and apnea in a critically ill patient induced by colistin neurotoxicity: key potential role of hemoadsorption elimination during continuous venovenous hemofiltration. Int. J. Nephrol. Renovasc. Dis. 6, 107-111. doi: 10.2147/IJNRD.S42791

Huang, Q., Liu, X., Cao, C., Lei, J., and Han, D. (2016). Apelin-13 induces autophagy in hepatoma HepG2 cells through ERK1/2 signaling pathway-dependent upregulation of Beclin1. Oncol. Lett. 11, 1051-1056. doi $: 10.3892 / 01.2015 .3991$

Jiang, H., Li, J., Zhou, T., Wang, C., Zhang, H., and Wang, H. (2014). Colistin-induced apoptosis in PC-12 cells: involvement of the mitochondrial apoptotic and death receptor pathways. Int. J. Mol. Med. 33, 1298-1304. doi: $10.3892 /$ ijmm.2014.1684

Kerr, J. F., Wyllie, A. H., and Currie, A. R. (1972). Apoptosis : a basic biological phenomenon with wide-ranging implications in tissue kinetics. Br. J. Cancer 26, 239-257. doi: 10.1038/bjc.1972.33

Komatsu, M., Waguri, S., Koike, M., Sou, Y. S., Ueno, T., Hara, T.,et al. (2007). Homeostatic levels of p62 control cytoplasmic inclusion body formation in autophagy-deficient mice. Cell 131, 1149-1163. doi: 10.1016/j.cell.2007.10.035

Kruse, J. P., and Gu, W. (2009). Modes of p53 regulation. Cell 137, 609-622. doi: 10.1016/j.cell.2009.04.050

Levine, B., and Klionsky, J. D. (2004). Development by self-digestion: molecular mechanisms and biological functions of autophagy. Dev. Cell 6, 463-477. doi: 10.1016/S1534-5807(04)00099-1

Li, X., Su, J., Xia, M., Li, H., Xu, Y., Ma, C., et al. (2016). Caspase-mediated cleavage of Beclin1 inhibits autophagy and promotes apoptosis induced by S1 in human ovarian cancer SKOV3 cells. Apoptosis 21, 225-238. doi: 10.1007/s10495-015-1197-y

Livak, K. J., and Schmittgen, T. D. (2001). Analysis of relative gene expression data using real-time quantitative PCR and the 2(-Delta Delta $\mathrm{C}(\mathrm{T})$ ) method. Methods 25, 402-408. doi: 10.1006/meth.2001.1262

Lu, Z., Jiang, G., Chen, Y., Wang, J., Muhammad, I., Zhang, L., et al. (2017a). Salidroside attenuates colistin-induced neurotoxicity in RSC96 Schwann cells through PI3K/Akt pathway. Chem. Biol. Interact. 271, 67-78. doi: 10.1016/j.cbi.2017.04.027

Lu, Z., Miao, Y., Muhammad, I., Tian, E., Hu, W., Wang, J., et al. (2017b). Colistininduced autophagy and apoptosis involves the JNK-Bcl2-Bax signaling pathway and JNK-p53-ROS positive feedback loop in PC-12 cells. Chem. Biol. Interact. 277, 62-73. doi: 10.1016/j.cbi.2017.08.011

Lu, Z., Xie, D., Chen, Y., Tian, E., Ishfaq, M., Chen, X., et al. (2017c). TLR2 mediates autophagy through ERK signaling pathway in Mycoplasma gallisepticum-infected RAW264.7 cells. Mol. Immunol. 87, 161-170. doi: 10.1016/j.molimm.2017.04.013

Maiuri, M. C., Galluzzi, L., Morselli, E., Kepp, O., Malik, S. A., and Kroemer, G. (2010). Autophagy regulation by p53. Curr. Opin. Chem. Biol. 22, 181-185. doi: 10.1016/j.ceb.2009.12.001

Mizushima, N., and Yoshimori, T. (2007). How to interpret LC3 immunoblotting. Autophagy 3, 542-545. doi: 10.4161/auto.4600

Mizushima, N., Yoshimori, T., and Levine, B. (2010). Methods in mammalian autophagy research. Cell 140, 313-326. doi: 10.1016/j.cell.2010.01.028

Nakai, A., Yamaguchi, O., Takeda, T., Higuchi, Y., Hikoso, S., Taniike, M., et al. (2007). The role of autophagy in cardiomyocytes in the basal state and in response to hemodynamic stress. Nat. Med. 13, 619-624. doi: 10.1038/nm1574

Nikoletopoulou, V., Markaki, M., Palikaras, K., and Tavernarakis, N. (2013). Crosstalk between apoptosis, necrosis and autophagy. Biochim. Biophys. Acta 1833, 3448-3459. doi: 10.1016/j.bbamcr.2013.06.001

Palumbo, C., Luca, A., Rosato, N., Forgione, M., Rotili, D., and Caccuri, A. M. (2016). c-Jun N-terminal kinase activation by nitrobenzoxadiazoles leads to late-stage autophagy inhibition. J. Transl. Med. 4:37. doi: 10.1186/s12967-016-0796-x

Pimkina, J., Humbey, O., Zilfou, J. T., Jarnik, M., and Murphy, M. E. (2009). ARF induces autophagy by virtue of interaction with Bcl-xl. J. Biol. Chem. 284, 2803-2810. doi: 10.1074/jbc.M804705200

Ryan, K. M. (2011). p53 and autophagy in cancer: guardian of the genome meets guardian of the proteome. Eur. J. Cancer 47, 44-50. doi: 10.1016/j.ejca.2010.10.020

Sasaki, N., Toda, T., Kaneko, T., Baba, N., and Matsuo, M. (2002). Flavonoids suppress the cytotoxicity of linoleic acid hydroperoxide toward PC-12 cells. Biol. Pharm. Bull. 25, 1093-1096. doi: 10.1248/bpb.25.1093

Sui, X. L., Jin, X., Huang, X., Geng, S., He, C., and Hu, X. (2011). P53 signaling and autophagy in cancer: a revolutionary strategy could be developed for cancer treatment. Autophagy 7, 565-571. doi: 10.4161/auto.7.6.14073

Tang, J., Di, J., Cao, H., Bai, J., and Zheng, J. (2015). p53-mediated autophagic regulation: a prospective strategy for cancer therapy. Cancer Lett. 363, 101-107. doi: 10.1016/j.canlet.2015.04.014

Tasdemir, E., Chiara, M. M., Morselli, E., Criollo, A., D’Amelio, M., DjavaheriMergny, M., et al. (2008a). A dual role of p53 in the control of autophagy. Autophagy 4, 810-814. doi: 10.4161/auto.6486

Tasdemir, E., Maiuri, M. C., Galluzzi, L., Vitale, I., Djavaheri-Mergny, M., D'Amelio, M., et al. (2008b). Regulation of autophagy by cytoplasmic p53. Nat. Cell Biol. 10, 676-687. doi: 10.1038/ncb1730

Thorburn, A. (2008). Apoptosis and autophagy: regulatory connections between two supposedly different processes. Apoptosis 13, 1-9. doi: 10.1007/s10495-007-0154-9

Vousden, K. H. (2007). Lane DP: p53 in health and disease. Nat. Rev. Mol. Cell Biol. 8, 275-283. doi: $10.1038 / \mathrm{nrm} 2147$

Wahby, K., Chopra, T., and Chandrasekar, P. (2010). Intravenous and inhalational colistin-induced respiratory failure. Clin. Infect. Dis. 50, 38-40. doi: $10.1086 / 650582$

Walkty, A., DeCorby, M., Nichol, K., Karlowsky, J. A., Hoban, D. J., and Zhanel, G. G. (2009). In vitro activity of colistin (polymyxin E) against 3,480 isolates of gram-negative bacilli obtained from patients in Canadian hospitals in the CANWARD study 2007-2008. Antimicrob. Agents Chemother. 53, 4924-4926. doi: 10.1128/AAC.00786-09

Wang, S. Y., Yu, Q. J., Zhang, R. D., and Liu, B. (2011). Core signaling pathways of survival/death in autophagy-related cancer networks. Int. J. Biochem. Cell Biol. 43, 1263-1266. doi: 10.1016/j.biocel.2011.05.010

Weinstein, L., Doan, T. L., and Smith, M. A. (2009). Neurotoxicity in patients treated with intravenous polymyxin B: two case reports. Am. J. Heal. Syst. Pharm. 66, 345-347. doi: 10.2146/ajhp080065

Zalckvar, E., Berissi, H., Eisenstein, M., and Kimchi, A. (2009a). Phosphorylation of Beclin1 by DAP-kinase promotes autophagy by weakening its interactions with Bcl-2 and Bcl-XL. Autophagy 5, 720-722. doi: 10.4161/auto.5.5.8625

Zalckvar, E., Berissi, H., Mizrachy, L., Idelchuk, Y., Koren, I., Eisenstein, M., et al. (2009b). DAP-kinase-mediated phosphorylation on the BH3 domain of beclin 1 
promotes dissociation of beclin 1 from $\mathrm{Bcl}-\mathrm{XL}$ and induction of autophagy. EMBO Rep. 10, 285-292. doi: 10.1038/embor.2008.246

Zhang, L., Xie, D., Chen, X., Hughes, M. L., Jiang, G., Lu, Z., et al. (2016). P53 mediates colistin-induced autophagy and apoptosis in PC-12 cells. Antimicrob. Agents Chemother. 60, 5294-5301. doi: 10.1128/AAC.006 41-16

Zhang, L., Zhao, Y., Ding, W., Jiang, G., Lu, Z., Li, L., et al. (2015). Autophagy regulates colistin-induced apoptosis in PC-12 cells. Antimicrob. Agents Chemother. 59, 2189-2197. doi: 10.1128/AAC.04092-14

Zhou, K., Sansur, C. A., Xu, H., and Jia, X. (2017). The temporal pattern, flux, and function of autophagy in spinal cord injury. Int. J. Mol. Sci. 18:E466. doi: $10.3390 /$ ijms 18020466

Zhu, B. S., Xing, C. G., Lin, F., Fan, X. Q., Zhao, K., and Qin, Z. H. (2011). Blocking NF-B nuclear translocation leads to p53-related autophagy activation and cell apoptosis. World J. Gastroenterol. 17, 478-487. doi: 10.3748/wjg.v17. i4.478

Conflict of Interest Statement: The authors declare that the research was conducted in the absence of any commercial or financial relationships that could be construed as a potential conflict of interest.

Copyright $\odot 2017$ Lu, Chen, Wu, Miao, Muhammad, Ding, Tian, Hu, Ni, Li, Wang and Li. This is an open-access article distributed under the terms of the Creative Commons Attribution License (CC BY). The use, distribution or reproduction in other forums is permitted, provided the original author(s) or licensor are credited and that the original publication in this journal is cited, in accordance with accepted academic practice. No use, distribution or reproduction is permitted which does not comply with these terms. 